\title{
ELECTRON ENERGY DISTRIBUTION, ELECTRIC FIELD AND TRANSPORT COEFFICIENTS IN THE FARADAY DARC SPACE
}

\section{E. Berger and A. Heisen.}

Sektion Physik der Universität Minchen, W. Germany.

The Faraday Darc Space FDS of an anomalous glow discharge is a good test object for the investigation of electron velocity distributions (EVD) in weak electric fields, because it is a transition region between the nearly field-free negative glow and the positive column.

The EVD was measured by double differentiation of a Langmuir probe characteristic $/ 1,2 /$. The work function of the probe surface is influenced by the probe current. This canbe eliminated by periodically potential measurement of a fixed point on the probe characteristic itself by sample and hold technics $/ 4 /$.

Together with a properly matched electronic circuit this procedure allows measurements of the second derivative over more than 4 decades with high accuracy.

The reduced electric field strength $\mathrm{E} / \mathrm{N}$ influences the EVD. Therefore it is possible to determine this parameter by comparison of the solutions of the Boltzmann 'equation

$$
\text { (1) } \frac{\partial f}{\partial t} j+\vec{v} \nabla_{r} f_{j}+\frac{e}{m}(\vec{E}+\vec{v} \times \vec{B}) \nabla_{v} f_{j}=B(\vec{r}, \vec{v}, t)
$$

with measured EVD's. We solved it for the electrons in the FDS of $\mathrm{a}_{2}$ glow discharge with following assumptions: stationary discharge without magnetic field; low ionization degree; use of the Lorentz approximation; maxwellian distribution for the neutral gas with temperature $\mathrm{Tg}$. Numerical values of the elastic $Q_{m}$ and inelastic $Q_{i}$ impact cross sections with the threshold potential $U_{i}$ were taken from an investigation in the $\mathrm{E} / \mathrm{N}$-range above $10 \mathrm{Td}$ made by Michel and winklex /5/. In the thermal range it was further necessary to take into account rotational excitation and deexcitation $Q_{-i}$ cross sections $/ 6,7 /$.

For the solution of the resulting differential equation system we assumed further: The EVD is in local equilibrium with the electric field $\mathrm{f}_{\mathrm{e}}(\overrightarrow{\mathrm{r}}, \overrightarrow{\mathrm{v}})=\mathrm{n}_{\mathrm{e}}(\overrightarrow{\mathrm{r}}) \cdot \mathrm{f}(\overrightarrow{\mathrm{v}})$ and the influence of density and field gradients are negligible with respect to the determination of transport parameters evaluated from the EVD $/ 8 /$.
The solutions of the resulting integro-differential equation

(2) $\left\{\left(\frac{E}{N}\right)^{2} \frac{M}{6 m} \frac{U}{\Sigma Q_{i}}+U^{2} \rho_{m} \frac{k T}{e} g\right\} \frac{d f(U)}{d U}+$

$$
\Omega_{m} U^{2} f(U)+\frac{M}{2 m} S I(U)=0 \quad \text { with }
$$

$S I(U)=\sum_{i}\left\{\int_{u}^{u+u_{i}} Q_{i}(\tilde{U}) \tilde{U} f(\tilde{U}) d \tilde{U}-\int_{u-u_{i}}^{u} Q_{-i}(\tilde{U}) \tilde{U} f(\tilde{U}) d \tilde{U}\right\}$ were compared with respect to the parameter $E / N$ with literature values for drift velocity and characteristic energy collected by Dutton /9/. They show good agreement $/ 10 /$.

From more than 300 local measurements of the EVD in the FDS performed in a bakable UHV discharge apparatus with cylindric symmetry we got the axial distribution of the different current parts shown in fig. 1 .

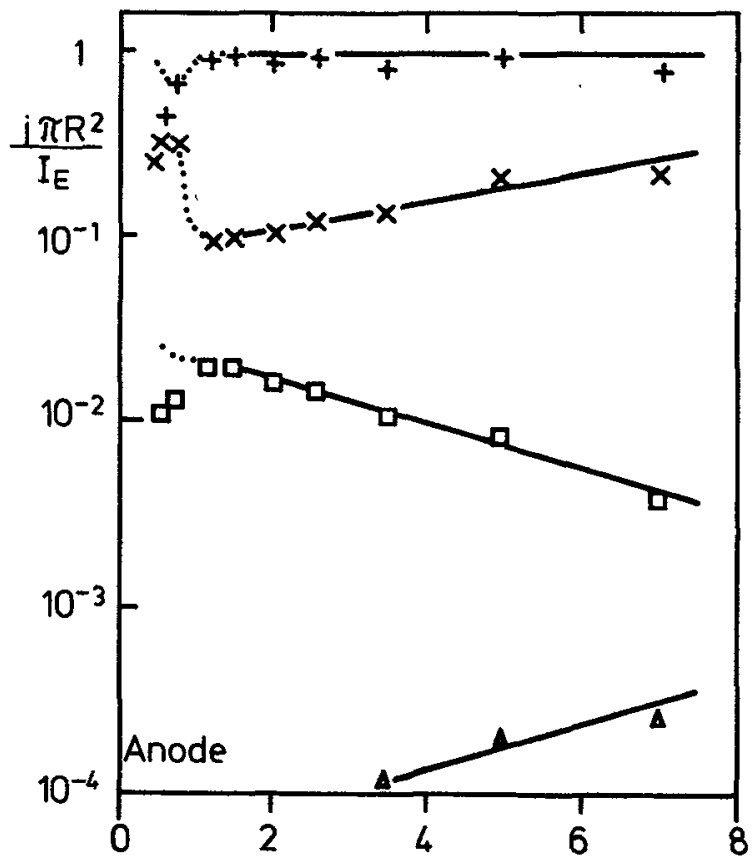

Fig. 1

Anode dist: $[\mathrm{cm}]$

Fig. 1

$+=e \mathrm{n}_{e} \mathrm{~b}_{e} \mathrm{E}_{z}$ : electron drift current

$\mathrm{x}=\mathrm{e} \mathrm{D}_{\mathrm{e}} \operatorname{grad}\left(\mathrm{n}_{\mathrm{e}}\right)$ : electron diffusion

$\square=e \mathrm{n}_{\mathrm{e}} \mathrm{b}_{+} \mathrm{E}_{\mathrm{z}}$ : ion drift

$\Delta=e D_{+} \operatorname{grad}\left(n_{e}\right)$ : ion diffusion 
$\mathrm{b}_{+}$and $\mathrm{D}_{+}$are the ionic transport coefficients for $\mathrm{H}_{3}{ }^{+}$ions in $\mathrm{H}_{2}$. By mass spectroscopy $\mathrm{H}_{3}{ }^{+}$was found to be the dominating ion.

Discharge parameters: tube diameter $60 \mathrm{~mm}$; spherical probe, diameter $1 \mathrm{~mm}$; discharge current $6.1 \mathrm{~mA}$ $\mathrm{H}_{2}$-pressure $51 \mathrm{~Pa}$.

Fig. 1 shows that the recombination loss of ions at the tube wall with the current density $j_{w+}$

(3) $j_{w+}=-e D_{a}(E / N) \cdot(d n / d r)_{R}$

$\mathrm{D}_{\mathrm{a}}$ : ambipolar diffusion coefficient, is compensated by the drift of ions comming from the anode region. The total loss of ions is given by

(4) $2 \pi R j_{w^{+}}=-2 \pi e \frac{d}{d z} \int_{0}^{R} b_{+} E_{z} n(r) r d r$

For approximate analytic survey we add the current transport equation $\left(n_{0}=n(x=0)\right.$ )

(5) $j_{0}=e n_{0} b^{E} E_{z}=I_{E} \cdot n_{0} /\left(2 \pi \int_{0}^{R} n(x) x d r\right)$

and a simplified field dependence of the ambipolar diffusion coefficient $D_{a}(E / N)$

(6) $\mathrm{N} \cdot \mathrm{D}_{\mathrm{a}}(\mathrm{E} / \mathrm{N})=\mathrm{E} / \mathrm{N} \cdot 1.6 \cdot 10^{36}\left[\mathrm{~s}^{-1} \mathrm{~cm}^{-1}\right]$ valid near $10 \mathrm{Td}$ in $\mathrm{H}_{2}$ at $300 \mathrm{~K}$ and for the ion mobility of $\mathrm{H}_{3}^{+}$we use

(7) $\mathrm{N} \cdot \mathrm{b}_{+}=3.01 \cdot 10^{20}\left[\mathrm{v}^{-1} \mathrm{~s}^{-1} \mathrm{~cm}^{-1}\right]$

The combination of (3) - (7) gives the axial dependence of the electron mobility in the FDS

(8) $-R^{2} \cdot N \cdot \frac{d}{d z} \ln \left(b_{e}\right)=$ const

From this equation we conclude: The local distribution of electron mobility is the determining mechanism for the axial extension of the FDS - in contrairy to the FDS-model of Ecker and Emeleus $/ 11 /$. The mobility determines the axial field and, taking into account the current transport equation, the charge density, too.

With respect to the numeric dependence $D_{a}(E / N)$, a numeric solution gives a good agreement with the experimental data shown in figs. 2 and 3.

Especially the strong decrease of the charge density near the anode is well reproduced (fig. 2). The sharp rise of the electric field (fig. 3) in this region is not reproduced, because the assumption of local equilibrium of the EVD with the field is not valid here.

Field measurements with a transversal electron beam confirm the strong rise of the electric field.

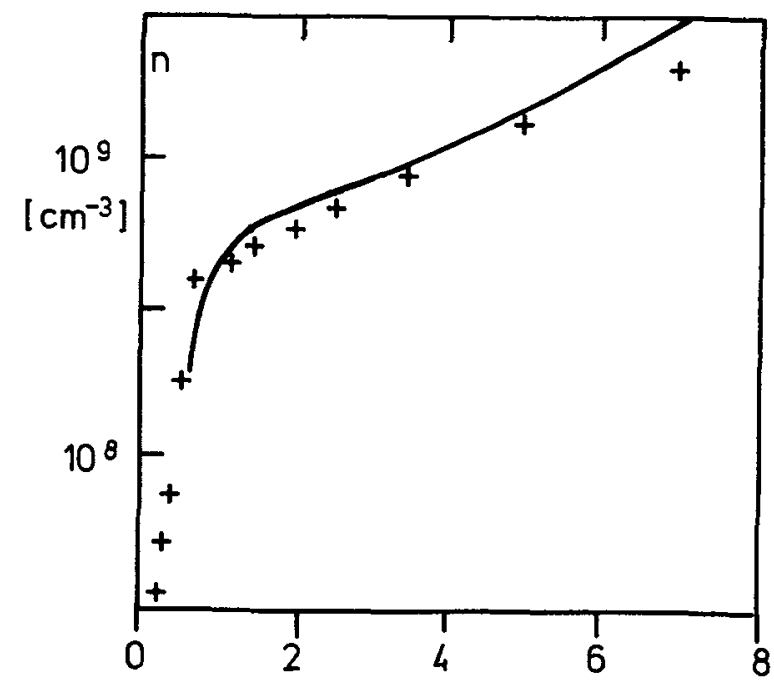

Fig. 2

Anode dist. $[\mathrm{cm}]$

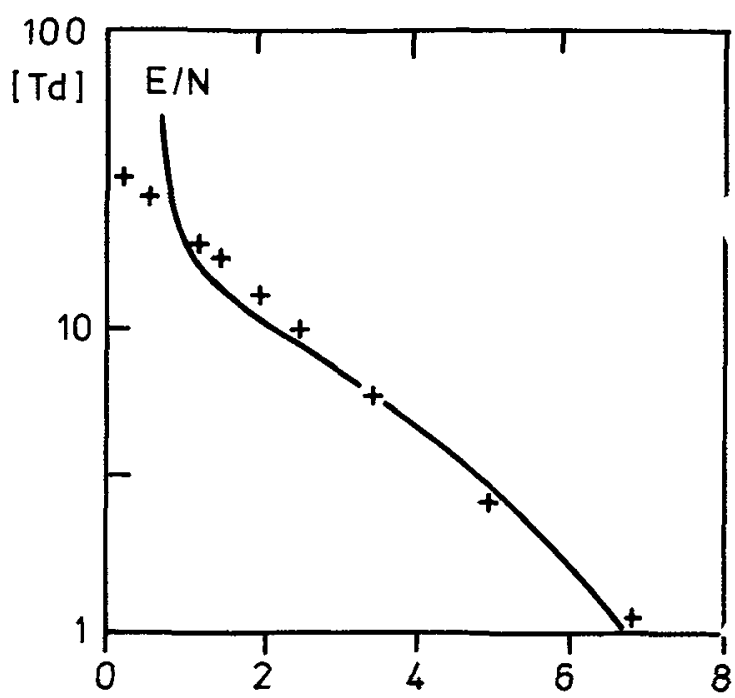

Fig. 3

11/ Druyvesteyn, M.J. 1930, Z.Phys. 64, 781-98

/2/ Berger, E., Heisen, A. 1975, J.Phys.D ㅁ, 629

/3/ D'ArCY, R.J. 1974, J.Phys.D 7, 1391

/4/ Wunderer, B.M. 1975, J.Phys.E 8, 938

/5/ Michel, P., Winkler, R. 1976, Beitr.Plasmaphys. 17,233

/6/ Crompton, R.W. et al. 1969, Aust.J.Phys. $\underline{22}$, 715

17/ Gibson, D.K. 1970, Aust.J.Phys. 23, 683

18/ Parker, J.H. jr., Lowke, J.J. 1969, Phys.Rev. 1,290

19/ Dutton, J. 1975, J.Phys.Chem.Ref.Data $\underline{4}$, No.3

/10/ Berger, E. 1979, Diss. Univ. München

/11/ Ecker, G., Emeleus, K.G. 1965, Ann.Phys. $\underline{7}$ No. 15,53 